\title{
La descentralización y la participación ciudadana a debate: un escenario de futuro complejo
}

\author{
Gorka Rodríguez Herrero \\ Universidad del País Vasco \\ gorka@partehartuz.org
}

\begin{abstract}
Resumen
Es el momento de la participación ciudadana. Los gobiernos locales apuestan por el impulso de procesos participativos como respuesta a las demandas de los colectivos sociales y vecinales, que reclaman canales para incidir en el proceso de toma de decisiones. Unas demandas que, en algunas ocasiones, los gobiernos locales han canalizado a través de procesos de descentralización utilizando el barrio o distrito como espacio de participación. En este contexto, nuestro principal objetivo es analizar los resultados de estos procesos en cinco municipios, visualizando las potencialidades y obstáculos en la definición de los tres grandes modelos que hemos creado: clásico-institucional, deliberativo-institucional e innovador-institucional. Los resultados son claros. En los tres modelos se visualizan realidades comunes con obstáculos para enriquecer la pluralidad de discursos por la dificultad de integrar a sectores de la sociedad excluidos en estos procesos. A su vez, se muestran carencias en la calidad de la deliberación del proceso de toma de decisiones y por último, los resultados suelen responder a políticas públicas de bajo perfil y con una escasa implicación ciudadana.
\end{abstract}

Palabras clave Gobiernos locales, desafección ciudadana, descentralización, participación ciudadana, evaluación de experiencias participativas.

\section{Decentralization and citizen participation brought into spotlight: a complex-future scenario}

\begin{abstract}
It is time for citizen participation. Local governments are committed to the promotion of participatory processes in response to the demands of social and neighborhood groups, who demand channels to influence the decision making process. Some claims that in some cases, local governments have channeled through processes of decentralization using the neighborhood or district as an area of participation. In this context, our main objective to analyze the results of these processes in the five boroughs, displaying the possibilities and obstacles in the definition of the three models we have created: traditional and institutional, deliberative, and innovative institutional and institutional. The results are clear. In all three models are displayed realities common obstacles to enhance the plurality of discourses about the difficulty of integrating the excluded sectors of society in these processes. In turn, show deficiencies in the quality of the deliberation of decision-making process and finally, the results tend to respond to public policies, low profile with little citizen involvement.
\end{abstract}

Key words

Local governments, civil indifference, decentralization, citizen participation, evaluation of participative experiences.

1 Este artículo tiene como base la tesis doctoral defendida en marzo de 2009 y financiada gracias a la beca pre doctoral del Programa de Formación de Investigadores del Gobierno Vasco (2004-2008).

Debo agradecer a Pedro Ibarra Güell la revisión crítica del artículo lo que indudablemente ha contribuido a su mejora. 


\section{INTRODUCCIÓN}

Las experiencias de participación ciudadana están conociendo una expansión sin precedentes de la mano de los gobiernos locales, en ocasiones unida a la descentralización administrativa. En este contexto se antoja necesaria una evaluación de esas experiencias participativas: a) ¿qué rendimientos/resultados generan?, es decir, en qué aspectos concretos se logra la mejora de la calidad de vida de la población gracias a la existencia de experiencias participativas y b) ¿se garantiza que los diferentes sectores sociales y ciudadanos (pluralidad sociológica) tengan presencia continuada en estas experiencias participativas?

Así, el objeto de estudio son las experiencias participativas y de descentralización desarrolladas en Bilbao, Vitoria-Gasteiz, Donostia-San Sebastián, Getafe y Córdoba, visualizando las potencialidades y obstáculos en la definición de los tres modelos creados y que permiten caracterizar las experiencias de participación analizadas: clásico-institucional, deliberativo-institucional e innovador-institucional. Los resultados son claros. En los tres modelos existen obstáculos para enriquecer la pluralidad de discursos por la dificultad de integrar a sectores excluidos en estas experiencias (juventud, mujeres, población inmigrante, tercera edad, personas en riesgo de exclusión social... ). A su vez, existen carencias en la calidad de la deliberación del proceso de toma de decisiones y, por último, los resultados suelen responder a políticas públicas de bajo perfil y con una escasa implicación ciudadana.

La estructura del artículo se desarrolla en cuatro apartados que describimos brevemente: a) un primer apartado teórico que pretende circunscribir las coordenadas y principios teóricos que guían la investigación posterior y que intentan explicar las razones de nuestro interés por el objeto de estudio; b) un segundo apartado en el que se definen los objetivos de la investigación. Se desarrolla el cuadro de indicadores de análisis y la metodología empleada para su desarrollo, los casos concretos elegidos para su análisis y los criterios utilizados para su elección; c) un tercer apartado que desarrolla la explicación de los tres modelos construidos a raíz de los resultados del análisis; y d) un apartado de conclusiones donde se delimita el debate final y se proponen interrogantes a futuro.

\section{2. ¿POR QUÉ SE HABLA TANTO DE PARTICIPACIÓN CIUDADANA?}

\subsection{Punto de partida: la desafección ciudadana}

El 15 de junio de 2008, a las 12:00 del mediodía, se celebró en Bilbao una manifestación organizada por la Coordinadora de Asociaciones Vecinales cuyo lema era "Porque los barrios también son de Bilbao. ¡Participación ciudadana ya!” Parece ser que

12 algo se está moviendo en el tejido asociativo de la villa y que cada vez más se está 
reivindicando una mayor participación activa para incidir en cuestiones de interés para los barrios y el municipio. Podríamos apuntar a un cierto resurgir del movimiento vecinal bilbaíno, y ciudadano en general, que si bien no es comparable al de la década de los setenta, sí parece que sufre de una cierta revitalización.

La manifestación en Bilbao parece apuntar a que el desasosiego o desafección democrática afecta a la salud de las democracias occidentales y es ya una referencia común en cualquier análisis politológico de cierta envergadura (Arbos y Giner, Barber, Bobbio, Held, Ibarra, Pasquino, Sartori, etc.). La desafección política no es algo novedoso y ya Di Palma lo definía en 1970 como ese sentimiento subjetivo de ineficacia, cinismo y falta de confianza en el proceso político, políticos e instituciones democráticas que generan distanciamiento y alineación, pero sin cuestionar la legitimidad del régimen político (Di Palma, 1970: 30; Torcal, 2001: 232). Autoras más recientes en el tiempo (Mouffe, 2003) observan la actividad de una fuerza negativa en la mayoría de las sociedades liberal-democráticas, una fuerza que contradice el triunfalismo que hemos presenciado desde el colapso del comunismo soviético. Una fuerza que parece acrecentar el cinismo respecto a la política y la clase política, influyendo de una manera negativa sobre la adhesión popular a ciertos valores democráticos (Dienel y Harms, 2000).

Así, diferentes ámbitos académicos y políticos apuntan a una crisis en el sistema de democracia representativa y de los fundamentos sobre los que se asienta (Pharr y Putnam, 2000). El resultado es una erosión del monopolio de la representación, sustentado en la incapacidad de la democracia representativa para recoger la creciente complejidad y la rápida transformación de las sociedades actuales (Prats, 2005). Esa rápida transformación de la sociedad tiene como máxima expresión una creciente emancipación del Estado lo que facilita un aumento de las demandas ciudadanas hacia el sector público, que no siempre se ven recompensadas ante el escaso rendimiento en políticas públicas eficientes del sistema democrático, generando desasosiego en la ciudadanía (Bobbio, 1985). Situación paradójica pues si bien los niveles de adhesión a la democracia como sistema político son elevados, ello no le exime de sufrir incisivas críticas ciudadanas. Una de las variadas razones a esta situación es el blindaje de los sistemas democráticos. Un blindaje sustentado en procesos electorales que no son espacios de deliberación y discusión sobre temáticas de interés ciudadano, sino que se han convertido en esferas de debate sobre quién debe ocupar el poder (Subirats, 1996).

Datos ilustrativos: en el caso de España (2002) casi el 90\% de la población consideraba que la democracia es preferible a cualquier otra forma de gobierno pero se muestra descontenta con su funcionamiento. Aproximadamente el $65 \%$ de la población española se mostraba satisfecha con el funcionamiento democrático del país, pero estos niveles no se han mantenido constantes: entre 1978 y 1989 la satisfacción con la democracia fue en aumento; a partir de esa fecha y hasta 1995 descendió acuciadamente, fecha en la que volvió a recuperarse llegando al año 2000 su nivel máximo del 70\% (Bonet et al., 2006: 127). 
Entre 1980 y 2002 ha aumentado 15 puntos el número de personas que opina que la ineficacia de la política es importante; a fecha de 2002 algo más del $70 \%$ de la población de España cree que la clase política no se preocupa de lo que opina la ciudadanía (Bonet et al., 2006: 114). Una pérdida de confianza que se manifiesta de una manera más acentuada en el caso de la población joven; en la mayoría de los casos, la juventud considera que su interés por la política es casi nulo y la opinión sobre su actividad es negativa (Ibarra et al., 2002: 23).

El común denominador de estos datos es que gran parte de la ciudadanía valora que la acción de gobierno cada vez se encuentra más alejada de sus necesidades y preocupaciones. Se considera que los cargos públicos condicionan los intereses de la ciudadanía a la disciplina de sus respectivas organizaciones partidistas, producto del modelo de sistema electoral y del peso de los aparatos o direcciones de los partidos. Desconfianza, indiferencia, irritación o aburrimiento son los sentimientos más extendidos entre la población hacia la política. El resultado más evidente de esta pérdida de confianza en el gobierno, que se expresa de muchas maneras, encuentra sus máximas manifestaciones en el desapego hacia la política y los políticos que manifiesta la ciudadanía o la progresiva minusvaloración de la política democrática como elemento útil para resolver el encuentro de intereses (OCDE, 2000: 23).

Además, la incapacidad de los partidos para controlar la agenda pública y el poder progresivo de los medios de comunicación de masas favorece la fragmentación del discurso político, que la dinámica política cotidiana sufra de una personalización excesiva y que la actividad política se haya traducido en la escenificación de lo escandaloso y en una supuesta ausencia de moral pública en la clase política (Ibarra et al., 2002). Como colofón los sistemas clásicos de representación se encuentran en una situación compleja por la falta de implicación de amplios sectores de la población (juventud, mujeres, población inmigrante, personas mayores, colectivos de excluidos sociales... ); la aparición de nuevas maneras de organización y movilización socio-política a través de ONG y nuevos movimientos sociales y por último la, a veces, mala fama de los partidos políticos (Tezanos, 2002).

\subsection{Hacia un cambio de paradigma en las administraciones públicas}

Los cambios políticos (desafección, globalización, gobernanza, gobierno multinivel... ) que afectan a nuestros sistemas democráticos influyen en la administración pública. Junto a la crisis de la democracia representativa nos encontramos con un cuestionamiento del modelo de administración pública. Tradicionalmente, la legitimación del sistema político democrático ha procedido de las actuaciones de la administración pública, sin embargo lo cierto es que sufre cambios importantes que afectan directamente a su legitimidad institucional y por rendimientos (Bañón y Carrillo, 1997). La adecuación de los regímenes democráticos ante los nuevos retos del siglo $14 \mathrm{XXI}$, y un cambio en el paradigma de la administración pública tendente a una mayor 
confluencia con las ideas de regeneración democrática, serán los dos grandes desafíos a futuro.

Así, las sociedades se están volviendo más diversas y plurales por los cambios que está imprimiendo la globalización, provocando que la gobernabilidad se vea afectada en la complejidad y fragmentación de las políticas públicas, influyendo a su vez en la administración pública. Una complejidad que hace la toma de decisiones más elaborada motivado por la necesidad de buscar acuerdos y crear puntos de encuentro y consenso en los que la ciudadanía debe jugar un papel de mayor protagonismo (Villoria, 1997; Subirats et al. 2008). Y para ello es necesario capacitar y ofrecer las condiciones necesarias a la ciudadanía para que pueda participar (Lowndes, Pratchett y Stoker, 2006).

La apuesta debería ser una administración pública que tiende a abandonar la relación jerárquica hacia la ciudadanía, basculando hacia una relación más horizontal e interdependiente (Nabaskues, 2003). Una opción que podría ahondar en esa mayor horizontalidad e interdependencia son las experiencias de participación ciudadana. El principal aporte en el abandono de esa relación jerárquica es el trabajo en red con diversos actores posibilitando la creación de una tercera vía que impulse el acercamiento entre la esfera pública estatal y la sociedad. En ese esquema de impulso de la participación ciudadana puede jugar un cierto papel (como lo ha hecho en el pasado) la propia descentralización administrativa. La descentralización como tal no es considerada un instrumento de participación pero lo cierto es que ha facilitado, en algunos casos, que los municipios establezcan espacios de participación facilitando el acercamiento de la administración a la ciudadanía por medio del diálogo y concertación de algunas necesidades (Gomá y Font, 2001).

Así, la relación de interdependencia entre la administración pública y los actores no estatales, a través de experiencias de participación ciudadana y descentralización administrativa, puede contribuir a la regeneración del sector público y a la creación de un organigrama más cercano a las necesidades de los agentes que componen la red. La ganancia fundamental son unas políticas públicas legitimadas por todos sus integrantes (Subirats et al., 2008).

\subsection{La revitalización de lo local y la regeneración democrática}

Los nuevos retos que se le presentan a la democracia representativa y a la administración pública invitan a pensar en el espacio de lo local como instrumento de revitalización democrática. El espacio de lo local es la nueva impulsora de las experiencias de participación ciudadana, entendidas como instrumentos que contribuyen a rediseñar las relaciones entre la ciudadanía y la democracia local. Por todo ello, el poder local ha evolucionado del concepto de Administración Pública Local al de Gobierno Local. Facilitando que la democracia local sea más deliberativa y reflexiva contribuyendo a una acción política más participativa y transparen- 
te. Así, la proximidad puede facilitar que la ciudadanía se relacione, delibere y cree ámbitos y marcos de referencia donde encontrar las posibles soluciones a sus necesidades. En este contexto, la descentralización administrativa puede ser un ingrediente que traduzca esa proximidad en políticas públicas pegadas al territorio. Entendiendo la descentralización como un proceso democratizador en el que no sólo se establezcan cauces de acceso a la democracia representativa, sino que contemple la presencia activa de la ciudadanía en el proceso de generación de las políticas públicas (Revello, 1999). Así, la democracia bascula de ser una actividad excepcional a un proceso permanente de apropiación de la realidad, de control creciente sobre los diferentes ámbitos de la vida cotidiana, de defensa y mejora de la calidad de vida de la ciudadanía (Céspedes, 2001). A una posible respuesta a la llamada crisis de las instituciones representativas y de las organizaciones burocráticas, y que podría solventarse a través de una relación directa público-privada y de autogestión social que puede desarrollarse en las ciudades (Blanco y Gomá, 2002; Stewart, 1996).

Estamos asistiendo, por tanto, a una "repolitización" de lo local o nuevo localismo democrático (Borja, 2000; Alguacil, 2006) producto de una ciudad que se ha convertido en un centro de atención política, económica, intelectual y cultural que le capacita para analizar los problemas y retos de las sociedades actuales (Borja, 1990). Todo ello lleva a gobiernos locales con capacidad para "definir un modelo social para el municipio, de explicitar los valores que lo informan, de construir un discurso legitimador con capacidad de concitar aportaciones y acuerdos amplios, de perfilar el alcance de la responsabilidad municipal, de transformar a ésta en opciones tangibles de política pública y de construir espacios de deliberación y de concertación social pluralista" (Brugué y Gomá, 1998: 47). Así, potenciar la democracia local es acercar la democracia a la gente, facilitar el control sobre la agenda gubernamental, hacer más comprensible la política, en suma, es un factor de profundización democrática (Villoria, 2005: 55). Los gobiernos locales deben ser pioneros en el proceso de profundización de la democracia, y ello con una mayor capacidad de flexibilidad, y anticipación ante los nuevos cambios y retos económico-sociales, políticos y administrativos (Canales Aliende y Pérez Guerrero, 2002: 131). Y parece que surgen experiencias que pretenden ejercer el gobierno local de una manera más integrada e innovadora hacia las políticas públicas orientadas hacia la ciudadanía (Rhodes, 2000; Sintomer, 2003; Stoker y Wilson, 2004).

Varias cuestiones ayudan en esa "repolitización" de lo local: a) la proximidad a la población en la gestión; b) la mayor capacidad de integrar las políticas públicas; c) la representatividad inmediata y directa de los gobiernos locales; d) la cultura cívica que considera iguales a todos los ciudadanos; e) la conciencia de identidad que los actuales procesos globalizadores han reforzado, como afirmación frente a la homogeneización (Borja, 2000: 3). Asistimos a un nuevo proceso de "glocalización" que reivindica el papel de las instituciones locales y regionales en las nuevas 16 coordenadas de los procesos decisorios, en donde se les garantice jurídicamente 
tanto su autonomía como su capacidad para ser sujetos políticos y ejercer el liderazgo (Borja, 2000)

La Carta Europea de la Autonomía Local² ahonda en el reconocimiento del nuevo localismo y de la "repolitización" de los gobiernos locales. De la mano del Comité de las Regiones y la Carta Europea de Autonomía Local los poderes regionales y locales han empezado a recobrar un cierto protagonismo, facilitando el desarrollo del principio de subsidiariedad y su plasmación en el propio ordenamiento jurídico comunitario. Impulsando que tanto el Comité de las Regiones como el Consejo de Europa se conviertan en los espacios de interlocución de los entes regionales y locales, dando un apoyo importante a las políticas de descentralización. Un impulso que aboga por una revisión del sistema competencial existente entre la Unión Europea, los Estados Miembros, sus Regiones y Municipios, facilitando que el principio de subsidiariedad encuentre su máximo desarrollo.

Los gobiernos locales del siglo XXI tienen entre sus retos aumentar su fortaleza en materia de competencias y de recursos, acompañándola de una labor política eficaz, caracterizada por la colaboración y concertación con la ciudadanía a través del impulso de espacios de deliberación. "El concepto de gobernación se hace en el ámbito local más palpable, dado que los Gobiernos locales necesitan ahora de la colaboración e implicación de los ciudadanos para diseñar y poner en práctica las políticas públicas para la ciudad" (Nabaskues, 2003: 53). Ahí es donde la "repolitización" de lo local encuentra su mayor apoyo.

\subsection{La evaluación de la participación ciudadana}

Los nuevos retos políticos (desafección, gobernanza, crisis de legitimidad...) han obligado a un replanteamiento en las pautas de actuación del gobierno local obligándole a ser el principal impulsor de experiencias de participación. El impulso de experiencias participativas se presta a una evaluación que dilucide en qué aspectos concretos se logra una mejora de la calidad de vida de población gracias a estas experiencias y en qué medida se generan espacios de diálogo y encuentro entre la ciudadanía y el gobierno local (mejorar la calidad de la democracia y de sus miembros) (Navarro, 2008).

Parece que existe un cierto consenso en aceptar que evaluar la participación a nivel local es más complejo que la simple aplicación de un conjunto de indicadores y

2 La Carta Europea de Autonomía Local es un tratado propiciado por el Consejo de Europa que fue ratificado por España en 1988. Entre su articulado se afirma que el derecho de los ciudadanos a participar en los asuntos públicos puede ser ejercido más directamente por el poder local, ya que éste constituye la Administración más próxima al ciudadano, así como que la defensa y fortalecimiento de la autonomía local representa un valor esencial en una Europa basada en la democracia y la descentralización del poder. 
que tampoco existe una amplia literatura al respecto (Navarro, 2008). Uno de los objetivos por el que es interesante evaluar las experiencias de participación ciudadana es la propia mejora de esas experiencias. Sin embargo, establecer un marco teórico que refuerce las razones por las que es conveniente evaluar es complejo. Y entendemos que es complejo porque las estrategias de evaluación y los instrumentos disponibles son muchos y diversos; y que las preguntas que rodean la evaluación son a su vez complejas, pues se mueven en registros distintos: qué se evalúa, para qué se evalúa, cómo se evalúa, quién evalúa (OIDP, 2006). Parece apuntarse a que determinadas formas de evaluación pueden ir hacia criterios más políticos y otros más instrumentales o metodológicos. Parece, así mismo, que el planteamiento de determinados teóricos (Navarro, 2008; Sintomer, 2003) es la de crear instrumentos de evaluación lo más completos y amplios posibles a través de una batería de indicadores que permitan un uso lo más flexible posible. Así, se apunta a la creación de una "Caja de Herramientas" que incorpore distintos criterios de evaluación, indicadores o posibles aspectos a evaluar y diversas metodologías para la evaluación de acuerdo con las características y los objetivos de cada caso.

El marco en el que podría moverse la evaluación de las experiencias de participación se circunscribiría en los siguientes aspectos:

- Análisis previo. La evaluación de una experiencia de participación exige un análisis detallado de cómo se ha integrado la misma en el proceso de toma de decisiones, qué agentes han tomado parte partiendo de su interés previo y cómo se ha de incorporar su participación y comentarios en el proceso. Para lo cual la preparación de una estrategia (previa) de evaluación producirá un mejor análisis a futuro.

- Integración con la toma de decisiones. Desde la perspectiva de la evaluación, es necesario que la inclusión de la participación forme parte de un proceso integral de toma de decisiones, esto es, que exista una integración clara de las actividades de participación y en la toma de decisiones. Por ello, resulta de gran utilidad analizar cómo se ha planificado la estrategia de participación.

- Coordinación interna. La implantación de una estrategia de participación eficaz requiere a menudo que se involucre a diversos departamentos dentro de una organización municipal, por lo que es importante averiguar qué estrategia se ha utilizado para definir responsabilidades, plazos de ejecución y procedimientos.

- Revisión de la gestión. La evaluación de las experiencias de participación debe servir para definir la estrategia de participación a desarrollar en futuros procesos. Así, la evaluación de la experiencia proporciona al equipo gestor municipal la información necesaria para fijar los recursos necesarios en futuras experiencias e interpretar mejor los aspectos más críticos e identificar cualquier problema en procesos posteriores. 
- Revisión por los agentes involucrados. La evaluación de experiencias de participación contribuye a aumentar la credibilidad de un proceso de toma de decisiones potencialmente controvertido dando a los agentes la posibilidad de revisar la estrategia de participación que se ha desarrollado.

\section{3. ¿QUÉ SE VA EVALUAR?}

Evaluar la participación ciudadana es un proceso complejo que sólo muy recientemente ha empezado a recibir la atención necesaria por parte de quienes trabajamos e investigamos esta realidad. Al respecto, merecen destacarse las aportaciones de Anduiza y Maya (2005), el Observatorio Internacional de Democracia Participativa (2006), Ajangiz y Blas (2008), Navarro (2008) todos estamos inmersos en un proceso compartido de construcción de variables, indicadores y criterios. Por el momento, el resultado es una "caja de herramientas" que contiene elementos e instrumentos de evaluación de la participación ciudadana, a seleccionar en cada caso de análisis en función de su pertinencia y relevancia específica.

Hemos hecho referencia a la "repolitización" de lo local como un fenómeno novedoso pero lo cierto es que en los últimos treinta años en los municipios españoles se han desarrollado políticas de descentralización administrativa que han tenido, en algunos casos, como una de sus principales apuestas la participación ciudadana. Sea como fuera, se antojaba necesaria una evaluación de estas experiencias pues entendemos que era una manera de impulsar espacios de deliberación y acercamiento entre el gobierno local y la ciudadanía.

Tradicionalmente se han elaborado estudios sobre los rendimientos que la descentralización administrativa ofertaba a los propios gobiernos locales, pero no se han realizado estudios que analicen las bondades u obstáculos que ésta ha supuesto para el impulso de la participación ciudadana. Alguacil (2005), Blas (2007), Borja (1987), Revello (1999) hacen referencia a la descentralización y el acercamiento de servicios como posibles instrumentos de impulso de la participación ciudadana.

\subsection{Objetivos}

La investigación persigue tres grandes objetivos:

- Analizar la calidad de los espacios de descentralización y participación ciudadana.

- Comparar los modelos de descentralización y participación ciudadana analizando sus obstáculos y potencialidades. 
- Averiguar si la descentralización administrativa es un factor determinante para el fomento de la participación.

Analizar la calidad de los espacios de descentralización y de participación ciudadana, tanto en resultados tangibles como en la valoración del proceso. Es decir, visualizar hasta qué nivel han cumplido los objetivos para los que fueron desarrollados: acercar la gestión municipal a la ciudadanía y democratizar las relaciones de poder creando los instrumentos necesarios para que los actores no estatales puedan incidir en aquellos asuntos del territorio que les preocupa (mejora de la calidad de vida).

Comparar los modelos de descentralización y de participación, analizando su evolución y capacidad de adaptación a las nuevas realidades así como de sus potencialidades y obstáculos de cara a los retos de futuro. Los contextos en los que se desarrollan, la implicación de los agentes, los recursos existentes, el historial participativo del territorio y el trabajo socio-comunitario previo pueden ser factores que condicionen los modelos de descentralización y de participación.

Averiguar si la descentralización administrativa puede ser un factor determinante que condicione la participación ciudadana. Hace 30 años, las asociaciones y colectivos sociales defendían la puesta en marcha de procesos de descentralización para tener una gestión municipal más cercana e incidir en asuntos de interés. La descentralización aparecía como un ingrediente muy importante en los primeros años de funcionamiento de los Ayuntamientos democráticos. Existía el convencimiento de que descentralizar era igual a más democracia y a más poder ciudadano, y que a la vez capacitaba para abordar los problemas ciudadanos. Ya lo veremos.

\subsection{Variables-criterio y metodología}

Tomando como referencia los objetivos marcados, el análisis se realiza a través de diversos indicadores en torno a tres grandes variables-criterio: la extensión y pluralidad de la participación (agentes), la organización de la participación y de la toma de decisiones (proceso), y los resultados y consecuencias de la participación (rendimiento). Para cada uno de los casos concretos se han aplicado las variables-criterio señaladas. 


\section{CUADRO 1}

Variables, indicadores y técnicas del análisis

\begin{tabular}{|c|c|c|}
\hline Agentes & ¿De qué hablamos? & Metodología \\
\hline $\begin{array}{l}\text { Extensión y } \\
\text { pluralidad }\end{array}$ & $\begin{array}{l}\text { Sectorial. Presencia suficiente de los cuatro ti- } \\
\text { pos básicos de agentes: personal político, pro- } \\
\text { fesionales y personal técnico, ciudadanía orga- } \\
\text { nizada y ciudadanía a título individual. } \\
\text { Ideológica. Presencia de los distintos discursos } \\
\text { y sensibilidades existentes en el territorio. } \\
\text { Sociológica. Presencia de los distintos colecti- } \\
\text { vos o grupos poblacionales con especial aten- } \\
\text { ción a las variables de sexo, edad, origen y vul- } \\
\text { nerabilidad o exclusión social. } \\
\text { Capacidad representativa en relación al grupo u } \\
\text { organización de procedencia. }\end{array}$ & $\begin{array}{l}\text { Recogida de datos sociode- } \\
\text { mográficos (fuentes muni- } \\
\text { cipales e institucionales). } \\
\text { Sociograma o mapa del teji- } \\
\text { do social en momentos dife- } \\
\text { renciados (realizados en los } \\
\text { casos de Bilbao y Vitoria) } \\
\text { Entrevistas en profundi- } \\
\text { dad }^{3} \text {. }\end{array}$ \\
\hline \multicolumn{3}{|l|}{ Proceso } \\
\hline $\begin{array}{l}\text { Organización } \\
\text { y toma de } \\
\text { decisiones }\end{array}$ & $\begin{array}{l}\text { Existencia y aplicación de normativa específica. } \\
\text { Agenda: inclusión y relevancia de las cuestiones. } \\
\text { Convocatoria y recogida de actas. } \\
\text { Horarios y formas de las sesiones. } \\
\text { Asignación de moderación/dinamización. } \\
\text { Deliberación y mecanismos de decisión. } \\
\text { Recursos disponibles (humanos, materiales, } \\
\text { económicos). } \\
\text { Transversalidad administrativa. } \\
\text { Participación ampliada (información activa y } \\
\text { mecanismos de consulta). } \\
\text { Compromiso con las resoluciones del mecanismo. } \\
\text { Existencia y funcionamiento de comisión de se- } \\
\text { guimiento. }\end{array}$ & $\begin{array}{l}\text { Revisión de documentación } \\
\text { y actas de los casos a anali- } \\
\text { zar para todo el periodo es- } \\
\text { tudiado: } 1977-2007 / 8 \text { (fuen- } \\
\text { tes municipales y de todo } \\
\text { tipo: aa.vv., colectivos socia- } \\
\text { les, institucionales...) } \\
\text { Observación: asistencia a } \\
\text { plenos y comisiones así } \\
\text { como a todas aquellas re- } \\
\text { uniones consideradas de in- } \\
\text { terés (realizado en el caso } \\
\text { de Bilbao, Vitoria y Córdoba) } \\
\text { Entrevistas en profundidad. }\end{array}$ \\
\hline \multicolumn{3}{|l|}{ Rendimiento } \\
\hline $\begin{array}{l}\text { Resultados y } \\
\text { consecuencias }\end{array}$ & $\begin{array}{l}\text { Impactos procedimentales. } \\
\text { Ciudadanía republicana. } \\
\text { Ganancias y consecuencias sustantivas en rela- } \\
\text { ción a la realidad inicial. } \\
\text { Satisfacción y aprendizaje. } \\
\text { Confianza social e institucional. } \\
\text { Competencia personal y grupal. } \\
\text { Fortalecimiento organizativo y vertebración re- } \\
\text { ticular de la ciudadanía. }\end{array}$ & $\begin{array}{l}\text { Revisión de documentación } \\
\text { y actas de los casos a anali- } \\
\text { zar para todo el periodo es- } \\
\text { tudiado: } 1977-2007 / 8 \text {. } \\
\text { Observación: asistencia a } \\
\text { plenos y comisiones así } \\
\text { como a todas aquellas re- } \\
\text { uniones consideradas de in- } \\
\text { terés. } \\
\text { Entrevistas en profundidad. }\end{array}$ \\
\hline
\end{tabular}

Fuente: Elaboración propia.

3 Destacar que el número de entrevistas realizado en el conjunto de la investigación asciende a más de 90. Aproximadamente unas 20 entrevistas por caso. En algunas circunstancias alguna persona era entrevistada en dos ocasiones por el interés que despertaba el aporte específico de información. En los 5 casos de estudio se han realizado las entrevistas a los siguientes perfiles: ámbito político, personal técnico y ciudadanía asociada. En algún caso concreto, por ejemplo San Sebastián, se incluyó alguna entrevista a ciudadanía no asociada ante la especial relevancia que despertaba. 
La extensión y pluralidad de la participación registra cuántos discursos están presentes en el mecanismo y cuál es su representatividad en relación a la realidad sociológica, entendida ésta como la inclusión de los distintos discursos e intereses presentes en el territorio, estén o no organizados. La realización de diversos mapas del tejido social nos ha permitido su evaluación.

El análisis de la organización de la participación y de la toma de decisiones abarca todas las variables de proceso: coordinación, formas, tiempos y procedimientos explícitos o implícitos de la participación en el mecanismo, recursos asignados, formato de la toma de decisiones, implicación e influencia de los distintos agentes en la misma, pero también iniciativas de difusión proactiva o participación ampliada en el proceso, cantidad y calidad de la temáticas abordadas y transversalidad administrativa.

Por último, los resultados y consecuencias analiza si la participación ciudadana ha cambiado las cosas y en qué medida, en relación a cuatro dimensiones: la satisfacción de las necesidades y demandas planteadas (ganancias y consecuencias sustantivas), la mejora o incorporación de procedimientos a favor de la participación e influencia ciudadana, las valoraciones y sentimientos de satisfacción y logro personal y comunitario, y el empoderamiento de la ciudadanía, organizada y a título individual, en relación a la representación política y la administración local.

El estudio de los indicadores-variable se ha plasmado en la elaboración de un completo cuestionario-guía de indicadores para extractar y ordenar la información disponible en la documentación y actas del mecanismo y así obtener información y contraste con los agentes implicados.

\subsection{Elección de criterios y de casos}

Entendemos que la elección de estos cinco casos obedece a los siguientes criterios: a) la apuesta estratégica que esos Ayuntamientos hicieron por el impulso de la participación ciudadana a través de la descentralización, $b$ ) la amplitud de temáticas que pueden abordar gracias a la descentralización de servicios, c) la presencia de una cierta variedad de agentes políticos, sociales y técnicos en las experiencias de participación a analizar y d) el hecho de que en su día fueran experiencias de referencia y muy valoradas tanto a nivel municipal como estatal.

Y para ello queremos analizar las principales experiencias consolidadas de descentralización y participación ciudadana que se han desarrollado en Bilbao, VitoriaGasteiz, Getafe y Córdoba. Evaluar experiencias de participación requiere que éstas tengan un cierto recorrido en el espacio temporal para poder analizar su evolución e impactos tanto sobre el Ayuntamiento (mejora en la toma de decisiones) como sobre la ciudadanía (mejora en la calidad de vida). Los gobiernos locales españoles 22 han puesto en marcha procesos de descentralización y participación ciudadana du- 
rante los últimos treinta años. Así, en los años ochenta, ciudades como Madrid, Barcelona, Zaragoza, Sevilla o Bilbao comenzaron a articular sus particulares modelos de descentralización y participación ciudadana (Borja, 1987; Villasante et al., 1993). Un dato: en el período de 1987-1991, es decir durante la tercera legislatura municipal, el 70\% de los gobiernos locales de más de 100.000 habitantes desarrollan reglamentos de participación (Gomá y Font, 2001). Unos reglamentos que acogen diferentes modalidades de descentralización vertebrándola con la participación ciudadana.

Por su parte a Donostia-San Sebastián la incluimos en experiencias novedosas, en clave de Plan de Desarrollo Comunitario (PDC). Entendíamos que la elección de una experiencia más reciente en el tiempo nos ayudaría a visualizar los aspectos comunes y divergentes en comparación a experiencias de mayor recorrido. No sólo en los impactos concretos en mejoras de la calidad de vida sino también en la manera de concebir la participación en comparación con las experiencias participativas de Bilbao, Vitoria-Gasteiz, Getafe y Córdoba.

CUADRO 2

¿Qué hemos analizado?

\begin{tabular}{|l|l|l|}
\hline \multicolumn{1}{|c|}{ ¿Qué ciudades? } & \multicolumn{1}{|c|}{ ¿Qué casos? } & \multicolumn{1}{c|}{ ¿Qué selección de políticas? } \\
\hline Bilbao & Consejo de Distrito (CD) & $\begin{array}{l}\text { Plan de urbanización de } \\
\text { Otxarkoaga, Proyecto Piloto } \\
\text { Urbano (PPU), Centro Cívico } \\
\text { (CC) y comisión sociocultural. }\end{array}$ \\
\hline Vitoria-Gasteiz & $\begin{array}{l}\text { Consejo Municipal } \\
\text { Descentralizado }\end{array}$ & $\begin{array}{l}\text { Centro Social Adurza (CS), Al- } \\
\text { caldía de barrio, Consejo Mu- } \\
\text { nicipal/ de Zona Olarizu (CMO/ } \\
\text { CZO), Concejalía Delegada de } \\
\text { Zona (CZD), Centro Cívico } \\
\text { (CC)y Consejo Territorial (CT). }\end{array}$ \\
\hline Donostia-San Sebastián & $\begin{array}{l}\text { Plan de Desarrollo Comunitario } \\
\text { de Alza (PDC) }\end{array}$ & $\begin{array}{l}\text { Camino escolar, Plan de urba- } \\
\text { nización de Oleta y Plan de ur- } \\
\text { banización de la Plaza Elizasu. }\end{array}$ \\
\hline Córdoba & Consejo de Distrito (CD) & $\begin{array}{l}\text { Seguimiento y análisis de polí- } \\
\text { ticas de urbanismo más signi- } \\
\text { ficativas. Análisis del funciona- } \\
\text { miento de los Centros Cívicos. }\end{array}$ \\
\hline Getafe & $\begin{array}{l}\text { Seguimiento y análisis de polí- } \\
\text { ticas en urbanismo más signi- } \\
\text { ficativas. Análisis del funciona- } \\
\text { miento de los Centros Cívicos. }\end{array}$ \\
\hline
\end{tabular}

Fuente: Elaboración propia. 


\section{CUADRO 3}

Casos y criterios utilizados

\begin{tabular}{|l|l|c|}
\hline \multicolumn{1}{|c|}{ ¿Qué ciudad? } & \multicolumn{1}{|c|}{ ¿Qué criterio temático? } & ¿Qué espacio temporal? \\
\hline Vitoria-Gasteiz & $\begin{array}{l}\text { Temáticas socio-culturales y orde- } \\
\text { nación urbanística }\end{array}$ & $1977-2006$ \\
\hline Córdoba & $\begin{array}{l}\text { Temáticas socio-culturales y orde- } \\
\text { nación urbanística }\end{array}$ & $1979-2007$ \\
\hline Getafe & $\begin{array}{l}\text { Temáticas socio-culturales y orde- } \\
\text { nación urbanística }\end{array}$ & $1983-2007$ \\
\hline Bilbao & $\begin{array}{l}\text { Temáticas socio-culturales y orde- } \\
\text { nación urbanística }\end{array}$ & $1987-2005$ \\
\hline Donostia-San Sebastián & $\begin{array}{l}\text { Temáticas socio-culturales y orde- } \\
\text { nación urbanística }\end{array}$ & $2002-2007$ \\
\hline
\end{tabular}

Fuente: Elaboración propia.

Además, la elección de los cinco casos de estudio obedece a dos criterios más: temático y temporal.

\section{Justificación del criterio temporal}

El marco temporal comienza en 1977 y finaliza en el 2007. Cada una de las ciudades-caso estudiadas tienen dos fechas, la más antigua hace referencia al año de inicio de la experiencia de descentralización y participación ciudadana y la fecha más reciente es el año en que concluyó la investigación. Así, obtenemos las suficientes referencias de las políticas y temáticas más relevantes.

\section{Justificación del criterio temático}

Los procesos de descentralización y participación ciudadana intentan responder a la crisis de los servicios urbanos y de los equipamientos básicos (falta de viviendas, de equipamientos sociales y educativos, imprevisión urbanística a todos los niveles, carencias de transporte, etc). Debido a esas carencias de las políticas urbanas españolas, las experiencias de descentralización se han fundamentado en el urbanismo y

气 los aspectos socioculturales para vertebrar la participación y abordar necesidades consideradas perentorias por las asociaciones. Además, en las experiencias analizadas parece que se entendía que la existencia de la descentralización ayudaría al desarrollo de la participación. Por lo tanto, entendemos que la descentralización no depende de la participación para su desarrollo, sino al revés: la participación necesita de la descentralización para su desarrollo. De hecho, así se entendía cuando se impulsa-

24 ron las experiencias analizadas. 


\subsection{Modelos de participación ciudadana y descentralización: obstáculos y oportunidades}

Los cinco casos se han analizado a través de las tres grandes variables-criterio, utilizadas como instrumentos analíticos que generan resultados para las conclusiones finales. Las que a su vez se han traducido en conceptos clasificatorios (limitado, más abierto y plural/inclusivo) resultado de las aportaciones y valoraciones de los agentes entrevistados sobre cada uno de los casos evaluados y de la información extraída en el proceso investigador. El desarrollo de los cinco casos de estudio, a través de las políticas analizadas, nos ha permitido la construcción de tres modelos de participación ciudadana y descentralización que caracterizan las experiencias analizadas pero no el modelo participativo de las ciudades objeto de estudio: el clásico-institucional (Bilbao y Getafe), el deliberativo-institucional (Vitoria-Gasteiz y Córdoba) y el innovador-institucional (Donostia-San Sebastián).

Añadir que el concepto institucional hace referencia a que las experiencias de participación, en mayor o en menor medida, son impulsadas por el Ayuntamiento. De ahí su diferenciación de experiencias de participación de impulso o base social/ciudadana. Aunque es cierto que no podemos hablar de modelos puros, pues cada uno de los casos tiene un poco de todos los modelos. A su vez, la categorización obedece a un intento por traducir la filosofía que impregna las experiencias de participación en conceptos más o menos entendibles: clásico, deliberativo e innovador. La categorización es intuitiva pero responde a los resultados obtenidos del análisis de los casos y encuentra su desarrollo, explicación y justificación en las siguientes líneas.

- Clásico-institucional: Entendemos este modelo como un instrumento donde las relaciones entre el gobierno local y la ciudadanía pasan por unas coordenadas muy definidas y poco flexibles (similares a la democracia representativa), basadas en unos esquemas de participación por invitación cuyo objetivo es mantener bajo control la participación. El objetivo es acercar servicios públicos y no tanto democratizar las relaciones de poder entre los agentes.

- Deliberativo-institucional: Este segundo modelo tiene unas concepciones más avanzadas que el clásico pues aunque es cierto que los esquemas de funcionamiento de los que parte son similares, pretende generar y construir espacios de deliberación y acuerdo entre la esfera institucional y la ciudadana. El objetivo es definir más o menos conjuntamente la construcción del interés general.

- Innovador-institucional: En este tercer modelo se intenta romper, o cuando menos superar, los tradicionales límites del modelo clásico, para así lograr un formato de participación diferente que modifique los instrumentos y capacidades de los agentes, mejorando la interacción y las sinergias ciudadano-institucionales. Con el objetivo último de regenerar en profundidad el sistema de democracia representativa, haciéndolo más flexible y permeable a las demandas ciudadanas. 


\section{CUADRO 4}

Resumen de las reflexiones

\begin{tabular}{|l|c|c|c|}
\hline \multirow{2}{*}{ Variables-criterio } & \multicolumn{3}{|c|}{ Modelos y su clasificación } \\
\cline { 2 - 4 } & Clásico-institucional & $\begin{array}{c}\text { Deliberativo- } \\
\text { institucional }\end{array}$ & $\begin{array}{c}\text { Innovador- } \\
\text { institucional }\end{array}$ \\
\hline Extensión y pluralidad & Limitado & Más abierto & Más abierto \\
\hline $\begin{array}{l}\text { Organización de la } \\
\text { participación y de la } \\
\text { toma de decisiones }\end{array}$ & Limitado & Más abierto & Plural/inclusivo \\
\hline $\begin{array}{l}\text { Resultados y } \\
\text { consecuencias }\end{array}$ & Limitado & Más abierto & Más abierto \\
\hline
\end{tabular}

Fuente: Elaboración propia.

\section{Pluralidad y extensión}

En el modelo clásico-institucional la pluralidad de la participación es limitada. En Bilbao y Getafe el esquema de participación no facilita una variada recogida de discursos y percepciones motivado por una serie de filtros. El reglamento de funcionamiento recoge una tipología de asociaciones y colectivos que no ha tenido modificaciones, reduciéndose a agentes sociales de corte muy tradicional: asociaciones vecinales, culturales-deportivas, asistenciales, comerciantes y AMPAS. Ese déficit ha provocado la preponderancia de esta tipología de colectivos, vecinales mayoritariamente, excluyendo a grupos feministas, organizaciones juveniles, movimientos pacifistas y anti militaristas, grupos ecologistas. Tal es así que sectores como la juventud o colectivos menos institucionales crean sus espacios de interrelación al margen de los consejos (creación de la coordinadora de grupos en el caso de Bilbao y de la coordinadora de jóvenes en Getafe).

Reducida presencia de la ciudadanía no asociada en los plenos de los consejos por la utilización de métodos tradicionales de información (actas públicas, pegada de carteles o folletos en la sede del consejo y en general los medios habituales que utiliza la administración para comunicar) que se han demostrado ineficaces para trasladar cuestiones que se abordan en los consejos. No existe una política de comunicación vertebrada e integral, sino que es puntual y de escaso atractivo. Todo ello provoca que la labor de comunicación ciudadana recaiga en asociaciones y colectivos sociales con una falta de relevo generacional que no garantiza el funcionamiento dinámico. De hecho, los canales de comunicación con la ciudadanía son, en ocasiones, voluntarios y poco sistematizados.

Otro filtro es la preponderancia cuantitativa y cualitativa de los partidos. Obedece a un esquema que no busca la ampliación y vertebración de los discursos y sensibi26 lidades ya que los partidos políticos disponen de más instrumentos para expandir su 
discurso: capacidad de voz y voto, regulación de los turnos de palabra, fomento de la presencia de la ciudadanía no asociada, contactos con sectores de población que consideren necesarios y establecer los límites de las temáticas que se abordan. Las comisiones de trabajo podían facilitar una mayor presencia de discursos y sensibilidades pero existe escasa permeabilidad y una falta de impulso en la creación de nuevas comisiones. La consecuencia principal es la falta de oxigenación y renovación de las sensibilidades sociales pues no penetran nuevos discursos lo que ahonda en temáticas memos amplias, acrecentando la distancia con el resto de la sociedad e impidiendo la construcción de nexos de diálogo estables.

En el caso de los Centros Cívicos (CC) prevalecen los criterios profesionales en los que prima una buena oferta de actividades con estructuras verticales con escasa capacidad para vertebrar los diferentes discursos. El personal técnico no está capacitado para recoger las diferentes sensibilidades de los agentes sociales ni se disponen de estructuras para ello; los CC son espacios para ofertar actividades socio-culturales y no para vertebrar los discursos y pluralidades del territorio.

La pluralidad y extensión de la participación en el modelo deliberativo-institucional es más abierto que el clásico-institucional aunque con limitaciones. Entre los debes: no existe una presencia reconocida y continuada de los discursos de sectores tradicionalmente excluidos de los espacios de participación (juventud, mujeres, personas con reducidos recursos económicos y culturales y minorías en general). El perfil mayoritario de asociaciones son las vecinales, asistenciales y deportivas porque se entiende que son los grupos que dinamizan la comunidad y tienen una mayor presencia en el territorio. Quedándose con una presencia muy limitada y discontinua los movimientos juveniles, ecologistas, feministas, antimilitaristas, etc.

Al igual que en el modelo anterior existe un importante déficit en la inclusión de la ciudadanía no asociada. La administración pública y las asociaciones y colectivos sociales utilizan instrumentos poco atractivos para comunicarse con la población. Sin embargo, se ensayan nuevas maneras de contactar con la población para recoger sus sensibilidades y percepciones (semana del vecindario, juegos y fiestas populares, exposiciones en la vía pública, fiesta de la primavera, etc.). Se está intentando sistematizar las maneras y formas de contacto entre las asociaciones y colectivos sociales con la ciudadanía no asociada haciéndolas más atractivas y sugerentes. Se nota una tímida oxigenación y renovación de los discursos y se muestra mayor sensibilidad en la inclusión de la pluralidad de percepciones del territorio a pesar de las limitaciones en el desarrollo de los recursos existentes y de sus potencialidades.

Destacar la relevancia otorgada a los discursos y percepciones de los agentes sociales en detrimento de los agentes político-partidistas, facilitando la incorporación de sus sensibilidades y dotándoles de un lugar preferente; presidencias de los consejos que recaen en los agentes sociales facilitando la incorporación de las sensibilidades y percepciones del territorio así como, experiencias de cooperación y concertación entre los agentes sociales fomentando la escucha y receptividad de los dis- 
cursos de sectores no presentes en el espacio de participación. Lo cierto es que se producen flujos y reflujos pues se observa un decrecimiento del número de sensibilidades y percepciones mientras que en otros momentos existe una sensible mejora en la inclusión de discursos excluidos. Son destacables los esfuerzos por vertebrar la inclusión de discursos y percepciones en los Centros Cívicos de Córdoba y VitoriaGasteiz a través de los consejos de centro o de experiencias similares, que no tuvieron el éxito deseado pero que dejaron un atractivo poso.

En el modelo innovador-institucional la pluralidad es más abierta que en los modelos anteriores, pero con deficiencias. Padece una falta de recursos y capacidades para conectar con aquellos sectores que no son tan visibles (población joven, mujeres, población inmigrante, minorías en general, etc.). Los motivos son la dificultad para llegar a la ciudadanía no asociada y el déficit de comunicación por la utilización de instrumentos tradicionales de comunicación (carteles, reuniones, asambleas, megafonía, convocatorias por carta o mensaje, etc.). No se llega de una manera muy clara provocando que la inclusión de los discursos ciudadanos sea costosa y sufra cortocircuitos. El escaso interés que despiertan en la ciudadanía los problemas que se abordan, aunque éstos tengan un carácter general, unido a que las movilizaciones se producen cuando los intereses individuales están en juego, provocan una importante desmovilización y desmotivación de la pluralidad de los discursos. Además, la junta de gobierno local debe presentar rendimientos para legitimar su acción de gobierno y a su vez, la administración pública funciona con formas de trabajo a más corto plazo lo que obliga a que no siempre se cuente con una riqueza óptima de discursos.

A pesar de las limitaciones se ha realizado un esfuerzo de inclusión del mayor número posible de discursos y sensibilidades aunque es inevitable una mayor movilización de los discursos de las asociaciones vecinales o de carácter más tradicional. Su discurso se encuentra más o menos presente frente al resto de colectivos que tienen más dificultades para tejer los discursos de la colectividad. A pesar de todo, se han impulsado espacios y políticas para la incorporación de los discursos más relegados, caso de la población infantil y juvenil, pero no se consigue la consolidación de la presencia de esos discursos. En el camino escolar (Donostia-San Sebastián) es destacable que el discurso de la población infantil y juvenil está incluida y desarrollada pero muestra dificultades para garantizar su presencia en otras políticas que se aplican en el territorio y que pueden afectar a este sector de la población.

A destacar el cambio en la administración pública en la incorporación de discursos excluidos en el diseño de políticas integrales. La creación de comisiones o espacios de trabajo conjunto contribuye a que cada área municipal traslade su discurso sobre determinada política y se contraste con las percepciones de las demás creando una mayor pluralidad discursiva. Con respecto a la clase política su presencia dentro de este modelo es muy discreta pues se entiende que sus discursos y sensibilidades se encuentran suficientemente representados y canalizados a través de los órganos 28 municipales. 


\section{Organización y toma de decisiones}

En el modelo clásico-institucional el proceso de toma de decisiones es limitado por el predominio del dirigismo político-institucional. Así, el esquema de participación de los consejos responde a la consulta puntual de cuestiones y a concepciones técnico-profesionales. Fomentando una participación de corto desarrollo donde la clase política marca el ritmo de los debates y del desarrollo de la agenda política, motivado por reglamentos de funcionamiento en los que no se ha contado con una participación amplia de los agentes sociales. Realidad que provoca dos efectos. El primero, que los reglamentos no suelen contar con el respaldo y legitimación de las asociaciones y colectivos sociales, pues su presencia en la elaboración de los mismos ha estado condicionada a la predisposición de los partidos políticos; y el segundo, son espacios donde se tiende a crear dinámicas de funcionamiento por y para los partidos. El producto es un reglamento en el que las premisas y concepciones sobre las que se asienta han perdido vigencia en una sociedad en proceso de cambio.

Este esquema refuerza que la clase política pueda vetar, a través del voto, los temas que no considera convenientes. De hecho es el personal político del consejo el que tiene la potestad para trasladar al Ayuntamiento las demandas o peticiones (a través de la secretaría del consejo), y sin necesidad de que los temas se pacten o acuerden con la parte social. Es cierto que los agentes sociales pueden incluir asuntos de interés pero en ocasiones sólo tienen como métodos para hacerse oír la presión y la movilización o que la clase política atienda sus peticiones en el pleno del consejo y acepte integrarlas para la próxima reunión. Con respecto a las actas públicas abunda un cierto oscurantismo y falta de transparencia puesto que no son de libre acceso o no están disponibles, lo que demuestra concepciones elitistas en el uso y la expansión de la información. Estamos, por tanto, ante una patrimonialización de la información que no facilita una sana deliberación. En los casos en los que la clase política muestra sensibilidad a las temáticas planteadas por las asociaciones, no dejan de ser hechos puntuales de escasa relevancia siendo la demora en abordar temáticas de mayor calado, la nota dominante. Los agentes sociales dependen no sólo de que la clase política acepte sus propuestas sino que el poder local las recoja o que exista una ventana de oportunidad política (gobierno municipal en minoría y una mayoría partidista en el consejo contraria a la Alcaldía; diferente correlación de fuerzas).

Las propias asociaciones apuestan más por la queja que por la deliberación, buscando abortar todas aquellas cuestiones con las que no se muestran favorables, pero sin capacidad para mostrar una alternativa clara. No existe una vertebración de las alternativas posibles y se tiene una visión un tanto corto placista de los problemas con unas actitudes poco inclusivas en la incorporación de aportaciones de otras asociaciones y colectivos, y escasamente proactivas frente a la institución. Todo ello se traduce en plenos de consejos donde no se trabaja el consenso y el acuerdo sino que se intenta trasladar a las comisiones de trabajo, en el caso de que existan. En ocasiones, los grupos de trabajo no muestran continuidad en el tiempo y no cuentan con objetivos claros que faciliten el interés de las asociaciones y colectivos sociales. La 
pertenencia a las mismas obedece a criterios de puro voluntarismo y para abordar temáticas de una forma parcelada y con escasa profundidad. Al final, ni las asociaciones ni la ciudadanía no asociada conoce su existencia con lo que la posibilidad para transmitir sus preocupaciones es prácticamente nula.

En otro orden de cosas, la limitada cooperación entre las áreas municipales provoca una escasa visión integral de los asuntos parcelando las demandas. En momentos puntuales existe un tímido trasvase de información hacia los consejos de distrito o de barrio pero obedece más a la presión social y asociativa y no tanto a la convicción de que es el mejor método de trabajo. El resultado: el Ayuntamiento asumirá las peticiones o compromisos que emanen de los consejos en función de la correlación de fuerzas existentes y de la valoración que extraiga de la demanda, considerándola apropiada o no. La posibilidad de generar conflicto o confrontación, tanto entre los partidos políticos como con los agentes sociales, será la variable que incline la balanza.

En el caso del modelo deliberativo-institucional la toma de decisiones es más abierta que en el anterior modelo, pues está basada en una concertación deliberativa donde se fomentan los puntos de encuentro sobre la materia a discutir. Una concertación deliberativa en la que están presentes el personal técnico y las asociaciones y colectivos, entendiendo la deliberación como el instrumento para lograr acuerdos sobre las temáticas y demandas que deben ser abordadas, contando con la participación del mayor número de agentes posible. Es un proceso deliberativo que se suele producir a dos bandas; por un lado, entre los agentes sociales para debatir las demandas que se le plantean al Ayuntamiento y por otro, entre los agentes sociales y el propio Consistorio o personal técnico para trasladar esas demandas e intentar llegar a un acuerdo para satisfacerlas.

Es cierto que en este modelo deliberativo-institucional suele existir una cierta predisposición a tomar en consideración las propuestas deliberadas pero siempre queda en manos del poder público adquirir un compromiso en su resolución. Lo cierto es que la capacidad de deliberar no suele ser recogida en los reglamentos pero se entiende que es la mejor manera de organizar la toma de decisiones. Así, la política deliberativa es fruto a su vez de un consenso en el que se asume que se debe desarrollar las decisiones de esta manera, permitiendo una cierta flexibilidad en la introducción e inclusión de las temáticas de interés. Como elemento negativo: la excesiva flexibilidad puede contribuir a la falta de compromisos de las partes implicadas al adoptar actitudes delegativas.

A pesar de las similitudes, lo cierto, es que el modelo se encuentra más desarrollado y consolidado en Córdoba fomentado por el área de Delegación de Participación Ciudadana. Una Delegación que realiza una labor de concertación y acuerdo con los agentes sociales, lo que ha favorecido la construcción de canales de diálogo y encuentro, gracias a los espacios de trabajo que están suponiendo los propios Centros Cívicos (CC) a pesar de la escasez de recursos. De hecho, en ocasiones han servi30 do para desperezar y limar actitudes muy poco participativas. En Vitoria-Gasteiz exis- 
te esa sensibilidad del poder local por el desarrollo de la concertación a través de la deliberación pero menos sistematizada y más relacionada con las sensibilidades e inquietudes participativas del personal técnico de cada CC. Lo cierto es que a pesar de las limitaciones esta situación se ha visto favorecida gracias a un tímido avance en la cooperación entre las áreas municipales, lo que ha facilitado que desde el Ayuntamiento se muestre una sensibilidad mayor hacia el trasvase de información a los agentes sociales y a que las áreas caminen poco a poco hacia una visión un poco más integral de las problemáticas.

Sin embargo existen limitaciones, pues la no presencia continuada de la clase política facilita la falta de compromiso para con la satisfacción de las demandas planteadas porque no son fruto del consenso, es decir, la clase política no ha sido partícipe de la elaboración de la demanda con lo que no se siente obligada a aceptarla. La inclusión del personal político puede contribuir a que las demandas concertadas de una forma deliberativa se traduzcan en consensos resolutivos en los que los cargos públicos se encuentran en la obligación moral de acatarlos puesto que también han contribuido a la construcción de ese consenso.

En el modelo innovador-institucional observamos que la organización de la toma de decisiones es plural/inclusiva pues se basa en una concertación deliberativa. Una concertación basada en la deliberación sin sustento normativo alguno, sencillamente ha sido el camino natural para integrar y armonizar los distintos intereses, tanto en el seno del Plan Desarrollo Comunitario (PDC) como en la relación con la ciudadanía no asociada. Una deliberación que continúa con unas pautas de desarrollo similares a las del modelo deliberativo-institucional pero que se diferencia de éste en que cuenta con más actores (plural/inclusivo). Por ejemplo, en el modelo innovador-institucional se garantiza una mayor riqueza de discursos a través de la inclusión de la población infantil-juvenil. En este caso se le facilitan canales y espacios de consulta para realizar labores de diagnóstico y deliberar conjuntamente con la población adulta sus necesidades y prioridades, haciendo que se sienta partícipe de la construcción colectiva de la sociedad. Convirtiendo el PDC en un espacio de encuentro, reflexión y deliberación entre los colectivos y asociaciones a pesar de la postura crítica que mucho de ellos mantienen frente al modelo. No existe una agenda pública diseñada previamente sino que las temáticas se abordan a medida que van surgiendo o son el producto de una política concreta que es demandada por el Ayuntamiento o por los colectivos sociales.

En ocasiones este modelo muestra deficiencias motivadas por un ejemplo típico de issue network: un espacio de concertación deliberativa sobre una extensa y variada agenda que no suele producir resoluciones operativas. Y cuando lo hace, no suele encontrar respuesta o receptividad en las instancias apeladas. Esta falta de respuesta es el resultado de una cadena de filtros. En primer lugar, los temas que se debatan, deliberen o consensúen están sujetos a que desde las instancias políticas se otorgue esa legitimidad. En función de las prioridades que establezca el Ayuntamiento, variarán el tipo de políticas que se trasladen al PDC, por ejemplo el camino escolar no ha 
surgido del plan de desarrollo o el caso de desarrollos urbanísticos (Auditz Akular); otro filtro a destacar sería la incertidumbre de los recursos económicos puesto que el plan carece de partida específica de inversiones de manera que en función de lo que se decida priorizar se pueden impulsar partidas presupuestarias para determinadas políticas (urbanización de las calles, mejora de la señalización, movilidad interna en el barrio o equipamientos de carácter social).

Unida a esta situación, en el modelo innovador-institucional los departamentos municipales muestran falta de porosidad a las demandas en políticas como cultura, educación, asuntos sociales, etc. A pesar de los intentos el resultado es una pobre cooperación interdepartamental que no garantiza la transversalidad necesaria para solucionar unas demandas territoriales que responden casi siempre a la tipología de cuestiones complejas.

\section{Resultados y consecuencias}

El modelo clásico-institucional bascula hacia resultados limitados porque las demandas y peticiones no siempre obtienen respuesta y cuando lo hacen es producto de condicionantes: gobierno municipal en minoría; grupos políticos gubernamentales en situación de desventaja en el consejo; capacidad de presión de los grupos políticos y de las asociaciones vecinales y colectivos sociales al margen del consejo y por último, el padrino partidista que cada asociación pueda tener. Todos estos factores en ocasiones uno por uno, y en otras todos juntos, pueden ser determinantes para que las demandas del consejo sean valoradas o tenidas en cuenta por el poder político. Así, las temáticas y demandas no son desarrolladas sin la complacencia de los partidos políticos haciendo de filtros a unas demandas que tienen relación con mejoras básicas en nivel y calidad de vida de los distritos o barrios. Entonces, ¿a qué se debe el escaso desarrollo de este modelo de descentralización y de participación?

Obedece a concepciones de la participación en la que ésta debe estar sometida a continua fiscalización. Los consejos como tales ya realizan esa labor. Sin embargo, el Ayuntamiento vuelve a filtrar sus peticiones a pesar de que en ocasiones cuentan con el apoyo unánime de sus miembros. El resultado de esta política de control provoca que para obtener resultados sea necesaria la utilización de canales y medios de presión al margen de los consejos, como movilizaciones o peticiones ante el gobierno local. Provocando la desmotivación y el desánimo entre los colectivos sociales presentes en los consejos y no logrando el refuerzo de la confianza social hacia los consejos como canales válidos de participación. Todo ello redunda en un modelo de escasa implicación ciudadana y con una reducida capacidad para regenerar su conciencia democrática y facilitar la construcción colectiva de sus demandas. El modelo no ha reforzado la confianza de las asociaciones, y creemos que ni de la ciudadanía en general, en las instituciones; es más, el nivel de desconfianza y de desafección es la nota 
Los motivos: existe la sensación de que la clase política no hace caso de las demandas que se le plantea y cuando lo hace es por sentido común o por la tenacidad de las asociaciones; se sienten infra-representados en comparación a los partidos políticos sobre todo por la escasa capacidad de incidir que tienen frente a la capacidad de voto; se han impulsado políticas públicas sin tener suficientemente en consideración la opinión de los consejos o sencillamente se han obviado durante años las demandas que se planteaban y, por último, son conscientes que el diseño de los consejos desincentiva la participación de las asociaciones y de la ciudadanía no asociada. Su diseño no facilita la entrada natural de los discursos y percepciones de los diferentes grupos sociales de manera que más costoso resulta lograr unas relaciones sociales y ciudadanas que refuercen la confianza social y grupal e impulsen espacios de fortalecimiento organizativo y de vertebración reticular de la ciudadanía.

Como elemento más positivo destacar que este modelo ha permitido crear un canal de comunicación permanente y reconocido entre los distritos y el Consistorio para satisfacer políticas de bajo perfil (mejoras de las aceras y del urbanismo en general, propuestas de creación de nuevas líneas de autobús, creación de equipamientos socioculturales, etc.) que mejoran puntualmente la vida cotidiana de la ciudadanía y que tienen el consejo como instrumento de impulso. Aún así, los consejos funcionan reivindicación por reivindicación con una escasa visión global de los problemas que impide abordar las políticas de una manera consensuada. No se invita a la reflexión conjunta de las demandas, en parte por los plazos electorales y también por la escasa cultura deliberativa de la clase política y de los colectivos sociales que funcionan más en clave de presión-cesión.

El modelo deliberativo-institucional se caracteriza por rendimientos más abiertos. Aunque es cierto que resulta tremendamente costosa la obtención de resultados claros, el modelo ha supuesto un balance positivo al poder canalizar la participación ciudadana y lograr una cierta mejoría en la calidad de vida. Dividiendo los resultados en dos grandes apartados, ganancias y consecuencias sustanciales en relación con la realidad inicial y mejora de la calidad democrática, obtenemos una importante disparidad. Es cierto que cuesta lograr que los poderes públicos tomen en consideración las demandas pero al final lo hacen motivados por la importante sistematización del trabajo realizado por los agentes sociales en justificar y razonar por medio de estudios, escritos o políticas de auto organización las intervenciones públicas que demandan; la tardanza de las instituciones ha supuesto que los distritos o barrios se unan y trabajen conjuntamente para la resolución de sus necesidades, haciendo del diálogo y el acuerdo los puntales fundamentales para satisfacer sus necesidades; en ocasiones la implicación del personal técnico ha sido razonablemente importante para trabajar conjuntamente con los agentes sociales y dotar de recursos y contenido técnico y profesional a unas demandas que, en ocasiones, no ahondaban en la causa fundamental de los problemas, y por último, la resolución de las necesidades planteadas ha supuesto un aliciente para seguir trabajando en los espacios de participación a pesar de las limitaciones. Es cierto que se ha mejorado, en cierto grado, la relación con el gobierno local y se han posibilitado la construcción de canales de encuentro, pero a nivel general no han sido suficientes. 
Con respecto a la mejora de la calidad democrática (ciudadanía republicana) existen importantes limitaciones. Los motivos: una cultura de queja demasiado asentada en las asociaciones y colectivos sociales que les impide desarrollar una interacción más profunda y sistematizada, tanto con el resto de asociaciones como con las instituciones; la existencia de canales y medios de participación que aunque son oficialmente reconocidos por el poder local sufren de falta de impulso, tanto en recursos como en el desarrollo de sus potencialidades (es el caso de los centros cívicos y de consejos de distrito y similares); una ciudadanía no asociada apática y que no visualiza la virtualidad de los espacios y canales que tiene para participar bien porque desde el poder político no se realiza una campaña de difusión o porque la desafección que sufren es tan fuerte que no vislumbran la utilidad de los mecanismos de participación y descentralización; un gobierno local que en ocasiones favorece la dilatación en el tiempo de la resolución de demandas ciudadanas que son razonadas por los agentes sociales y, por último, un personal técnico desafecto, tanto en el Ayuntamiento como en los espacios de participación, que en ocasiones no es consciente de su importante papel de mediador en las demandas ciudadanas hacia los órganos competentes.

En el caso del modelo innovador-institucional los rendimientos que ofrece son más abiertos porque se han mejorado los resultados procedimentales penetrando en la estructura (procedimientos) del Ayuntamiento y mostrando una mayor sensibilidad para abordar las demandas ciudadanas. Sin embargo, sigue pendiente una mayor celeridad en la resolución de las demandas y en mejorar los rendimientos tangibles que siguen siendo demasiado difusos. Es cierto que se han logrado mejoras en la calidad de vida pero se desconoce si es producto de los beneficios del propio modelo o de políticas que desarrolla el Ayuntamiento al margen del mismo. La mayoría de los agentes entrevistados reconocen que se ha experimentado una cierta mejora en la calidad de vida, pero desconocen si son el producto del PDC. De hecho, del diagnóstico de necesidades inicial que se realizó desconocen su nivel de cumplimiento. Por tanto, el modelo funciona más como un espacio de interrelación o de deliberación entre las asociaciones y colectivos sociales, y no tanto como un instrumento de transformación de la realidad.

Si bien el modelo innovador-institucional puede funcionar como un canalizador de voluntades, creando y generando un espacio de encuentro y de debate, lo cierto es que no existen políticas definidas que sean impulsadas por el plan comunitario. Las políticas analizadas han sido canalizadas a través del plan pero no impulsadas por él, facilitando la concertación y el encuentro, pero falta audacia y capacidad de iniciativa ô y por último, es bastante limitada su capacidad para modificar el rumbo de las políti$\stackrel{0}{2}$ cas que se fraguan en el Ayuntamiento y cuando se logra, es producto de la presión de los agentes sociales. Además, la participación de la ciudadanía a título individual se ha producido en casos puntuales y motivada por políticas que afectaban a sus intereses individuales. Por todo ello, el modelo muestra limitaciones para crear una ciudadanía republicana y virtuosa comprometida con la búsqueda del interés general y el 34 bien común pero sí es un espacio que facilita la defensa de las necesidades ciudada- 
nas, aunque en ocasiones no lo consigue con demasiado éxito. En definitiva, es un modelo que responde a un cambio de actitudes y de sensibilidades (sobre todo por parte del Ayuntamiento) pero que no repercute de una manera directa y sustancial sobre la mejora de la calidad de vida.

Finalmente, parece cierto que las propuestas de interés ciudadano cuando son validadas por los agentes sociales Ilegan formalmente al gobierno municipal pero en ocasiones son ignoradas o vuelven a la oficina del plan con una respuesta insatisfactoria. Las actas y documentación dan fe de estas cuestiones. La mayoría de los agentes implicados reconocen que es una manera de construir las relaciones entre la administración y los colectivos sociales y que, por lo tanto, se necesitará tiempo para analizar sus resultados. A pesar de las limitaciones, lo cierto es que los propios agentes sociales reconocen que la existencia de este modelo les ha permitido tener a su disposición un mayor número de canales y de instrumentos para dialogar y conocerse, facilitando que los puntos de fricción o de desacuerdo se canalicen. Tampoco creemos que el modelo innovador-institucional esté suponiendo hoy por hoy un vuelco en la vertebración del proceso de toma de decisiones público, pero lo cierto es que es un modelo que, dentro de la institución, supone ligeros avances y cambios en las formas de concebir el poder y de la relación de éste con la sociedad.

\section{CONCLUSIONES}

A continuación, recapitulando los tres objetivos de la investigación hacemos un balance de los retos que se les presentan a los tres modelos.

- Calidad de las experiencias de descentralización y de participación ciudadana: resultados insuficientes en la mejora de la calidad de vida de la población y dificultades importantes en incorporar a la ciudadanía en el proceso de toma de decisiones.

Destacaríamos que en los tres modelos creados la relativa parquedad de resultados podría estar motivada, entre otras cuestiones, por la escasa flexibilidad de la administración en las maneras de incorporar discursos sociales. Los complejos procesos burocráticos facilitan el distanciamiento de las asociaciones de su base social, pues emplean demasiado tiempo en la resolución de los problemas burocráticos que supone trasladar las demandas a las instituciones. Contribuyendo a que la desafección ciudadana hacia lo público se incremente ante la complejidad de los trámites burocráticos. De hecho, en los tres modelos, los colectivos sociales deben adoptar pautas de trabajo de la administración pública cumpliendo los plazos, horarios y los procedimientos requeridos para ser atendidos o simplemente trasladar sus propuestas.

La solución pasaría por una mayor transparencia de la administración y facilitar una mayor flexibilidad en los canales de contacto con el tejido social, mostrando mayor sensibilidad a las formas de trabajo de las asociaciones. Sobre todo si tenemos en cuenta que la globalización está creando sociedades mucho más plurales e interde- 
pendientes que necesitan de canales fluidos de información (Villoria, 1997; Subirats et al., 2008).

Pero existen otros retos que impiden que la obtención de resultados tangibles sea mejor. Así, el desafío de la deliberación nos obliga a facilitar instrumentos que permitan una discusión rica, ampliando los temas locales a ámbitos superiores. Lo cual no significa que logremos la implicación de la ciudadanía pues la realidad es que ésta se abstiene de estos procesos. Sobre todo teniendo en cuenta el hastío que demuestra la población ante procesos electorales que no cumplen su función deliberativa (Subirats, 1996). De manera que será necesario realizar esfuerzos por incorporar a todas las personas que están dispuestas a participar y que su posible ausencia no esté motivada por una falta de recursos para ello. El reconocimiento público de los canales de acceso facilitaría esa inclusión y podrían mejorar a la larga los resultados en la calidad de vida y en el acercamiento de servicios.

- Comparar los modelos de descentralización y de participación: ninguno de ellos es plenamente satisfactorio en la recogida de los diferentes discursos sociales por una escasa implicación ciudadana, una información escueta y poca flexibilidad.

El fomento de la pluralidad de discursos se debería fomentar a través de dinámicas de inclusión de los agentes sociales y de la ciudadanía no asociada. Es necesario que los tres modelos (clásico, deliberativo e innovador) impulsen la remodelación de saberes haciéndolos más democráticos y plurales. Utilizando como herramienta planes de formación que ayuden a que los/as "no expertos/as" aporten sus percepciones sin que su formación profesional sea un mérito o demérito y poniendo el conocimiento en manos de la ciudadanía. Dotar a la ciudadanía de instrumentos para trasladar sus discursos facilitaría la inclusión de los sectores excluidos (especialmente las mujeres) de los espacios de participación, en línea con la inclusión que plantea Tezanos (2002), de sectores de la población con problemas de inclusión en los espacios de participación.

A su vez las asociaciones deberían conectar más con su base social y ciudadana, e impulsar el relevo en sus cúpulas dirigentes de cara a descargar responsabilidades y facilitar la fluidez de la información. Además, la reforzada profesionalización de los conocimientos del personal técnico consolida su centralidad en las decisiones ante una clase política que no tiene la suficiente formación y una ciudadanía que demanda servicios de calidad. Por ello, también es importante que vean la participación como una manera distinta de trabajar; el reto consiste en visualizar la participación como algo necesario y que permite la flexibilización de las formas de trabajo sin menoscabar o desplazar las aportaciones del personal técnico sino enriqueciéndolas.

Por otro lado, sería necesaria la obtención de mejoras en la calidad de vida, relacionado con lo que comentan Bañón y Carrillo (1997) de la legitimidad por rendimientos, y en la capacidad para generar una deliberación democrática. Entendida como el 36 ejercicio continuado de compartir información y opiniones, analizar la información y 
las situaciones enriquecidas por las experiencias y la visión de los demás, confrontando las opiniones, escuchando, expresándose, asumiendo responsabilidades, rindiendo cuentas y recibiendo críticas. Todo ello será viable cuando exista también una política de devolución que permita visualizar a los agentes implicados sus aportes específicos, reforzando el sentimiento de inclusión. Una devolución que sea clara y comprensible para todos/as, sin engaños y lecturas torcidas porque de lo que estamos hablando es de la capacidad de incidencia real dejando claro cuál ha sido el grado de influencia tangible de cada agente.

- La descentralización administrativa es un factor importante que puede condicionar la participación ciudadana, facilitando o entorpeciendo las interacciones entre los poderes locales y el tejido social en el marco de la participación por invitación (de la institución a la ciudadanía).

Hace 30 años, las asociaciones y colectivos sociales defendían la puesta en marcha de procesos de descentralización para tener una gestión municipal más cercana e incidir en asuntos de interés. La descentralización aparecía como un ingrediente muy importante en los primeros años de funcionamiento de los Ayuntamientos democráticos. Existía el convencimiento de que descentralizar era igual a más democracia y a más poder ciudadano, y que a la vez capacitaba para abordar los problemas ciudadanos.

La conclusión fundamental es que los procesos analizados fueron impulsados para acercar los servicios públicos a la ciudadanía y democratizar las relaciones de poder a través de la creación de espacios de participación. Sin embargo, parece que si bien la descentralización no era un factor fundamental a la hora de impulsar la participación es cierto que contribuía a ello en tanto ayuda a que la administración sea más cercana a la ciudadanía y menos jerárquica contribuyendo a crear una relación más interdependiente. No tanto por la posibilidad de gestionar competencias, sino por la virtualidad de que se plasme en políticas públicas en las que la ciudadanía interviene en su definición en el territorio/barrio. Facilitando así una intervención ciudadana en el debate público y logrando una mejor calidad democrática del sistema representativo. La realidad en los tres modelos es que la descentralización no se ha explotado todo lo deseable y que en la práctica el número de competencias ha sido muy escaso, centrándose sobre todo en la ordenación urbanística y en políticas socioculturales. No parece que en el caso de los tres modelos creados el principal problema fuera la atrofia sufrida en la descentralización (ya hemos visto que tienen otros asuntos igual de importantes) pero parece claro que quizás el desarrollo de una política descentralizadora más ambiciosa hubiera facilitado algunos de los retos ya planteados.

- Retos a futuro: A la sombra de estos tres modelos encontramos ejemplos de importantes espacios de vertebración de la participación, conjugando el territorio y los servicios de proximidad como los principales ingredientes a desarrollar. La realidad cotidiana de nuestros municipios parece apuntar a una revitalización de los equi- 
pamientos de proximidad como nexos de unión y desarrollo de la participación a través del territorio, incorporando la visión ciudadana de una forma vertebrada. Parece que asistimos a un cierto cambio en los modelos, que tienen en los Centros Cívicos la referencia instrumental. Las tendencias apuntan a los equipamientos de proximidad como los nuevos referentes de la participación y el acercamiento de servicios municipales, y la creación de redes municipales ${ }^{4}$ así lo confirman.

Si esa revitalización es real deberíamos estudiar: 1) qué se entiende por criterios de proximidad y los instrumentos necesarios para reforzarla y conectarla con la participación ciudadana; 2) cómo se vertebran las relaciones con las áreas del Ayuntamiento, con las asociaciones y ciudadanía a título individual y con el resto de equipamientos de proximidad del municipio; 3) qué instrumentos existen para generar una administración relacional y que es uno de los principios sobre los que se asienta los pilares de los equipamientos de proximidad; y 4) qué diferencias existen en la manera de acercar servicios municipales a la ciudadanía y facilitar la participación, con respecto a los modelos más tradicionales de descentralización administrativa (consejos de distrito o de barrio).

\section{REFERENCIAS BIBLIOGRÁFICAS Y DOCUMENTALES}

Alguacil, J. (2005), “Los desafíos del nuevo poder local: la participación como estrategia relacional en el gobierno local”, Revista Académica de la Universidad Bolivariana, 12: 1-16. En línea:<http://www.revistapolis.cl> (consulta: 15 marzo 2008).

- (2006): Poder local y participación democrática. Madrid: El Viejo Topo.

Ajangiz, R. y Blas, A. (2008), Mapa de experiencias de participación ciudadana en los municipios del País Vasco. Vitoria-Gasteiz: Gobierno Vasco.

Anduiza, E. y Maya, S. (2005), La qualitat en la participació: una proposta d'indicadors. Finestra Oberta 43. Barcelona: Fundació Jaume Bofill.

Arbos, X. y Giner, S. (1993), La gobernabilidad. Ciudadanía y democracia en la encrucijada mundial. Madrid: Siglo XXI.

Bañón, R. y Carrillo, E., comps., (1997), “La legitimidad de la administración pública”, en R. Bañón y E. Carrillo, eds., La nueva administración pública. Madrid: Alianza.

Barber, B. (2000), Un lugar para todos. Cómo fortalecer la democracia y la sociedad civil. Barcelona: Paidós.

Blanco, I. y Gomá, R. (2002), “Proximidad y participación: marco conceptual y presentación de experiencias”, en I. Blanco y R. Gomá, coords., Gobiernos locales y redes participativas. Barcelona: Ariel.

Blas, A. (2007), "El reto de la descentralización participativa en el ámbito local. Un acercamiento a los problemas y las disyuntivas", en I. Ahedo y P. Ibarra, eds., Democracia participativa y desarrollo humano. Madrid: Dykinson.

Bobbio, N. (1985), Crisis de la democracia. Barcelona: Ariel. 
Bonet, E., Martin, I. y Montero, J. R. (2006), “Las actitudes políticas de los españoles”, en J. R. Montero, J. Font, y M. Torcal, eds., Ciudadanos, asociaciones y participación en España. Madrid: CIS.

Borja, J. (1987), Descentralización y participación ciudadana. Madrid: Instituto de Estudios de Administración local.

Borja, J. et al. (1990), "Políticas y gobierno en las grandes ciudades", en J. Borja, M. Castells, R. Dorado e I. Quintana, Las grandes ciudades en la década de los noventa. Madrid: Editorial Sistema.

- (2000), "Ciudad y ciudadanía: dos notas", Working Papers. N. ${ }^{\circ} 177$. Barcelona: Institut de Ciencies Politiques i Socials.

Brugué, Q. y Gomá, R. (1998), Gobiernos locales y políticas públicas: bienestar social, promoción económica y territorio. Barcelona: Ariel.

Canales Aliende, J. M. y Pérez Guerrero, P. L. (2002), Introducción al gobierno y a la gestión local. Alicante: ECU.

Céspedes, J. M. (2001), “La participación ciudadana desde el ámbito municipal”, en M. Marchioni, coord., Comunidad y cambio social: teoría y praxis de la acción comunitaria. Madrid: Editorial Popular.

Di Palma, G. (1970), Apathy and Participation. Mass Politics in Western Societies. Nueva York: The Free Press.

Dienel, P. y Harms, H. (2000), Repensar la democracia. Los Núcleos de Intervención Participativa. Barcelona: Ediciones del Serbal.

Gomá, R. y Font, J. (2001), “La democracia local: un mapa de experiencias participativas”, en J. Font, coord., Ciudadanos y decisiones públicas. Barcelona: Ariel.

Held, D. (1997), La democracia y el orden global. Del Estado moderno al gobierno cosmopolita. Buenos Aires: Paidós.

Ibarra, P.; Gomá, R. y Martí, S. (2002), “Los nuevos movimientos sociales. El estado de la cuestión”, en P. Ibarra, M. Salvador y R. Gomá, coords., Creadores de democracia radical. Movimientos sociales y redes de políticas públicas. Barcelona: Icaria.

- (2008), Relational Democracy. Reno: Nevada University Press.

Lowndes, V.; Pratchett, L. y Stoker, G. (2006), "Diagnosing and remedying the failings of official participation schemes: the CLEAR framewok", Social Policy and Society 5(2): 281-291.

Mouffe, C. (2003), La paradoja democrática. Barcelona: Gedisa.

Nabaskues, I. (2003), Globalización y nueva política local. Bilbao: Instituto Vasco de Administración Pública.

Navarro, C. (2008), “Los rendimientos de los mecanismos de participación: propuesta de sistema de evaluación y aplicación al caso de los Presupuestos Participativos", Revista del CLAD Reforma y Democracia, 40: 1-15.

Observatorio Internacional de Democracia Participativa (OIDP) (2006), Guía práctica: evaluación de procesos participativos. Barcelona: OIDP.

Organisation for Economic Co-operation and Decelopment (OECD) (2000), Goverment of the future. Nueva York: Oxford University Press.

Pasquino, G. (2000), La democracia exigente. Madrid: Alianza.

Pharr, S. y Putnam, R., eds., (2000), Disaffected Democracies: What's Troubling the Trilateral Countries? Princeton: Princeton University Press. 
Prats, J. (2005), De la burocracia al management, del management a la gobernanza. Las transformaciones de las administraciones públicas de nuestro tiempo. Madrid: Instituto Nacional de Administración Pública.

Revello, M. del R. (1999), “Descentralización y participación: la experiencia montevideana”, Revista CIDOB d'Afers Internacionals, 47: 149-169.

Rhodes, R. A. W. (2000), The New Politics of British Local Governance. Oxford: Oxford University Press.

Sartori, G. (2003), ¿Qué es la democracia? Madrid: Taurus.

Sintomer, Y. (2003), Porto Alegre: la esperanza de otra democracia. Madrid: Debate.

Stewart, J. (1996), "Innovation in democratic practice in local government", Policy and Politics, 21(1): 17-28.

Stoker, G. y Wilson, D. (2004): British Local Government into the 21st Century. Londres: Unwin Hyman.

Subirats, J. (1996), “Democracia: participación y eficiencia”, Gestión y Análisis de Políticas Públicas, 5-6: 35-45.

- et al. (2008), Análisis y gestión de políticas públicas. Barcelona: Ariel

Tezanos, J. F. (2002), La democracia incompleta. Madrid: Biblioteca Nueva.

Torcal, M. (2001), "La desafección en las nuevas democracias del sur de Europa y Latinoamérica", Revista Instituciones y Desarrollo, 8-9: 229-280.

Villasante, T. R. et al. (1993), “Experiencias de participación ciudadana en municipios: análisis y propuestas", Alfoz 104-105: 87-96.

Villoria, M. (1997), “Modernización administrativa y gobierno postburocrático”, en R. Bañón y E. Carrillo, eds., La nueva administración pública. Madrid: Alianza.

- (2005), "Democracia y participación”, en La participación ciudadana en grandes ciudades. Madrid: Universidad Rey Juan Carlos.

Recibido: 22 de julio de 2009

Aceptado: 23 de noviembre de 2009 